\title{
Los tiempos de la sociedad hispano colonial: un contraste de los registros escritos de visitas y juicios de residencia
}

\section{Silvina Smietniansky}

\section{(2) OpenEdition Journals}

Edição electrónica

URL: http://journals.openedition.org/aa/2214

DOI: $10.4000 / a a .2214$

ISSN: 2357-738X

Editora

Programa de Pós-Graduação em Antropologia Social (UnB)

\section{Edição impressa}

Data de publição: 1 dezembro 2016

Paginação: 95-126

ISSN: 0102-4302

\section{Refêrencia eletrónica}

Silvina Smietniansky, «Los tiempos de la sociedad hispano colonial: un contraste de los registros escritos de visitas y juicios de residencia», Anuário Antropológico [Online], v.41 n.2 | 2016, posto online no dia 15 junho 2018, consultado o 27 abril 2021. URL: http://journals.openedition.org/aa/2214 ; DOI: https://doi.org/10.4000/aa.2214

\section{(c) $)(9)$}

Anuário Antropológico is licensed under a Creative Commons Atribuição-Uso Não-Comercial-Proibição de realização de Obras Derivadas 4.0 International. 


\title{
Los tiempos de la sociedad hispano colonial: un contraste de los registros escritos de visitas y juicios de residencia
}

\author{
Silvina Smietniansky \\ CONICET/UNQ
}

El estudio del tiempo en antropología se desarrolló a partir del abordaje de otros aspectos de la vida social (economía, política, religión, ritual, parentesco, etc.) y en ese sentido antes que ser tratado como un problema unitario, quedó fragmentado en diversos tópicos y campos de estudio (Munn, 1992). Este artículo, de hecho, se desprende de una investigación que focalizaba la dimensión ritual del poder en las instituciones de gobierno en Hispanoamérica colonial. ${ }^{1}$ El tiempo, que comprendía un aspecto más en el estudio de los rituales examinados, fue cobrando una densidad tal hasta convertirse en un problema en sí mismo. Las fuentes que habían sido seleccionadas en función de otras preguntas y otros debates teóricos e historiográficos fueron reexaminadas en vista de un nuevo objetivo: aproximarse a los modos de representar y registrar el tiempo que pueden advertirse a través de la documentación producida en el marco de dos instituciones que formaban parte de los dispositivos de control con que contaba la monarquía hispana en la administración de sus dominios americanos. La visita y el juicio de residencia definieron ese recorte institucional y, en continuidad con trabajos anteriores, su conceptualización como rituales es una de las claves de análisis.

\section{El tiempo en los documentos coloniales: una propuesta de análisis}

Como veremos, el análisis comparativo de los expedientes resultantes de visitas y residencias parte de interrogar la relación entre las categorías temporales que allí aparecen y las prácticas y fenómenos sociales que a cada institución le competían. Distintos enfoques se han aproximado a este problema. ${ }^{2}$ Bajo la mirada durkheimiana (Durkheim, 2007; Durkheim \& Mauss, 1971), el tiempo ubicado en el plano de las representaciones sociales y las categorías colectivas impuestas a los individuos se explica a partir de la morfología y los ritmos de la vida social. La visión pragmática de Malinowski (1927), despojada de la vestimenta mítico-ritual que le otorgara Durkheim, analiza el cálculo del tiempo como un medio para la organización de las actividades, mientras que Evans-Pritchard (1977), si bien se hace eco de estas aproximaciones, aborda el "tiempo ecológico" en términos de procesos y de movimientos estacionales que implican las actividades concretas. 
Esta idea puede rastrearse en el estudio de Mauss (1974) sobre las variaciones estacionales en la sociedad esquimal, aunque en Los nuer, operando a la par del "tiempo ecológico", Evans-Pritchard además distingue un "tiempo estructural" que, en su análisis, asume un carácter más abstracto y cuya segmentación se basa en los ciclos de las relaciones sociales. Munn señala que esta noción aportó a la construcción de un "modelo ilusorio del tiempo", destacando entre sus referentes el estudio de Geertz (1992) sobre cómo la cultura balinesa "destemporaliza" la experiencia intersubjetiva del tiempo. También allí ubica la propuesta de Bloch (1977), quien crítica las ideas de Durkheim sobre el carácter socialmente determinado de la cognición y abreva de los aportes de Malinowski al comparar el tiempo en contextos rituales y no-rituales. Si bien discute el análisis de Geertz sobre el caso balinés, Bloch distingue entre un modelo en que el tiempo —estático - se disuelve y despersonaliza a los individuos, característico de la comunicación ritual, y un sistema que responde a la comunicación cotidiana vinculado a las experiencias empíricas, que involucra conceptos universales y que trasciende los contextos culturales particulares. De acuerdo con la ocasión, los sujetos apelan a una u otra conceptualización del tiempo. Otros enfoques posteriores harán hincapié en la práctica y la acción (Bourdieu, 2013) y, poniendo sobre relieve la experiencia histórica de los sujetos, también en los usos políticos y estratégicos del tiempo (Smith, 1986; Thompson, 1967).

Bajo diferentes aproximaciones, el carácter socialmente construido del tiempo ha conducido a reparar en las categorías temporales que utilizan los actores, los sistemas calendáricos, los ritmos estacionales de la vida social, las perspectivas y relatos sobre el pasado, las transformaciones en los modos de calcular el tiempo a partir de cambios producidos en el ordenamiento político, entre otros aspectos. ${ }^{3}$ En nuestro caso, el trabajo con documentos escritos obliga inevitablemente a colocar el foco en el discurso, en las categorías locales que aparecen en las fuentes, situadas en los contextos intersubjetivos de uso. Esto no supone que los términos deban contener una referencia temporal explícita; Johannes Fabian (1983), al analizar la construcción del objeto antropológico, muestra el modo en que ciertas categorías, como primitivo y salvaje, marcan un distanciamiento temporal entre dicho objeto y el productor del discurso antropológico, funcionando de forma simbólica, connotando el tiempo.

Los expedientes elaborados durante el desarrollo de las visitas y los juicios de residencias son el resultado de múltiples diálogos que, conducidos bajo determinados protocolos, involucraron a jueces y asistentes, escribanos, testigos, imputados y defensores. A través del análisis de estos procedimientos ocupados en indagar la realidad de las sociedades locales exploramos los modos en que ciertos 
aspectos de la vida social resultaban temporalizados a partir de la estructura, los objetivos y los interrogatorios que guiaron la actuación de los magistrados (representantes del rey) como de los relatos que ofrecieron testigos e imputados. ¿Qué marcos temporales imponían cada una de estas instituciones orientadas a producir información sobre los dominios españoles en América? ¿Qué discursos temporales pueden advertirse en las declaraciones y testimonios de los vecinos y funcionarios del Tucumán para el caso de las residencias y de los indios y encomenderos en el marco de la visita?

Esas preguntas involucran dos aspectos del estudio del tiempo. Por un lado, el cálculo del tiempo, es decir, a partir de qué categorías culturales el tiempo es referido y qué orden de acontecimientos se colocan en relación. ${ }^{4}$ Por otro lado, entendemos que ese abordaje puede arrojar indicios de las perspectivas locales sobre la propia sociedad, en las cuáles se conjugan nociones de cambio, de regularidad cíclica y de continuidad. El repertorio etnográfico e histórico no sólo da muestras del modo en que diferentes sociedades han desarrollado diversos modos de medición y representación del tiempo, sino también de que esa diversidad se reproduce al interior de cada sociedad. Valeri (1990) apunta que en cualquier pueblo que haya desarrollado un discurso sobre el pasado, las representaciones de la relación entre pasado y presente difícilmente puedan reducirse a un sistema monolítico de modelos que se replican idénticamente a lo largo del tiempo y que revierten en una disolución de la temporalidad. ${ }^{5}$ Las representaciones del pasado en términos históricos y míticos coexisten: el presente puede buscar en el pasado los modelos a seguir y, en ese ejercicio, pasado y presente son comparables (relaciones paradigmáticas), e incluso el pasado es cuestionable; pero también pueden identificarse eventos del pasado únicos y extraordinarios que explican el origen y el carácter incuestionable de la sociedad y sus instituciones (relaciones sintagmáticas). El poder del pasado para legitimar el presente puede basarse en el cambio como en la continuidad.

En este trabajo, la diversidad de miradas sobre el tiempo surge de la comparación entre una visita y un juicio de residencia llevados a cabo en la gobernación del Tucumán. Hasta fines del siglo XVIII, esta jurisdicción ocupaba el noroeste y una porción del centro del actual territorio argentino, formaba parte del Virreinato del Perú con capital en Lima y respondía a la órbita judicial y administrativa de la Audiencia de Charcas (en la actualidad, la ciudad de Sucre). Estaba integrada por las ciudades de Salta, Jujuy, Tucumán, Catamarca, La Rioja, Santiago del Estero y Córdoba. La residencia del gobernador y la sede del Episcopado, fijadas en un comienzo en Santiago, fueron luego, en el siglo XVIII, trasladadas a Salta y a Córdoba, respectivamente. 
Los gobernadores, al igual que el resto de los funcionarios coloniales, cuando cesaban en sus cargos debían someterse a un juicio de residencia destinado a evaluar su obrar al mando de la provincia y a mejorar las instituciones de gobierno a partir de reconocer sus falencias. ${ }^{6}$ En estos casos, también eran juzgados quienes hubieren ejercido oficios públicos en el gobierno local - el cabildo - durante el mandato del gobernador residenciado. El procedimiento duraba 60 días y constaba de dos fases principales. En la fase pública, el magistrado tomaba declaraciones individuales a una serie de testigos sobre el desempeño de los funcionarios residenciados y examinaba los libros e instalaciones del cabildo y de la cárcel. Luego, en la pesquisa secreta, los particulares podían promover demandas y querellas contra los imputados por haber sido perjudicados por alguno de ellos o tener conocimiento sobre su mal comportamiento. En ambos casos, el juez levantaba cargos contra los funcionarios y éstos procedían con su defensa. Este artículo analiza el juicio de residencia instruido al gobernador Juan Victorino Martínez de Tineo, llevado a cabo entre fines de 1763 y comienzos de 1764, cinco años después de concluido su mandato (1754-1759). Las referencias temporales que aparecen a lo largo del extenso expediente que incluye testimonios directos y transcripción de documentos de gobierno son variadas. Entre ellas, la cronología segmentada en ańos, el mandato de los gobernadores, las elecciones anuales del cuerpo capitular y la misma celebración de la residencia cuyo despliegue perturbaba los ritmos de la vita cotidiana.

Por su parte, las visitas también tenían como objetivo exigir las responsabilidades correspondientes a los oficios públicos y mejorar la observancia de las normas, pero presentaban un carácter más variado y podían desarrollarse en cualquier momento mientras el funcionario estaba en el ejercicio del cargo. Podían ser generales para relevar el panorama de toda una jurisdicción o responder a situaciones o problemas específicos. Entre 1692 y 1694, Antonio Martínez Luján de Vargas, oidor de la Audiencia de Charcas, llevó a cabo una visita general a la gobernación del Tucumán que tuvo como objeto reconocer el estado en que se encontraba población indígena bajo el sistema de encomienda y desagraviar a los naturales en caso de comprobar abusos y malos tratos por parte de los encomenderos.? Para ello, recorrió cada una de las ciudades del Tucumán, replicando un mismo modelo de indagación, aunque aquí nos centraremos apenas en la jurisdicción de La Rioja. Frente a las preguntas del juez, los declarantes (indios y encomenderos) acudían tanto a los ritmos de los ciclos agrícolas y las actividades productivas como a la duración y momento de inicio de la relación de explotación — servicio personal - que ligaba a encomendados y encomenderos, entre otras referencias temporales en las que pasado y presente prestan una línea de continuidad. 
La amplitud temporal que considera este artículo responde a la disponibilidad de fuentes y al campo empírico explorado hasta esta instancia de la investigación. ${ }^{8}$ El trabajo con materiales de archivo plantea muchas veces la necesidad de aproximarse a ciertos temas a través de fuentes dispersas, incompletas, con informaciones disparejas sobre espacios geográficos y períodos históricos, y que han sido producidas para otros fines muy diferentes a los del investigador. No obstante, una mirada "a contrapelo" debe complementarse con un enfoque que atienda a la lógica de producción y circulación de los documentos, reparando no sólo en el contenido sino también en la forma y la significación que adquiere el mismo ejercicio de escritura, conservación y clasificación de estos extensos expedientes (Barton \& Papen, 2010; Hull, 2012; Stoler, 2002). En ese sentido, el análisis del corpus documental transcurre a través de dos ejes. Por un lado, examinamos el contenido de los testimonios en búsqueda de categorías temporales o de expresiones que aún sin referencias temporales explícitas funcionaran temporalizando el objeto de los discursos, atendiendo especialmente a las representaciones de las relaciones entre pasado y presente. Por otro lado, reconocemos que esos discursos temporales fueron ellos mismos producidos en el marco de eventos ritualizados y extraordinarios en el contexto de las sociedades locales, que seguían un orden secuencial, aunque la organización de los expedientes redefinió, en parte, esa experiencia del tiempo.

Como vemos, este artículo discurre entre el quehacer del historiador y el del etnógrafo. Los materiales de archivo definen nuestro campo empírico, acercándonos a la tarea del primero; sin embargo, la manera de interrogar las fuentes, plantear el problema de investigación, las preguntas e interpretaciones abreva de una aproximación etnográfica, en particular, de conceptualizar visitas y residencias bajo la noción de ritual. Catherine Bell (1992) observa que el ritual se constituyó de modo integral en un objeto de estudio y un método de análisis. Se trata de una categoría sociológica que ha sido utilizada en el estudio de la religión, la sociedad y la cultura, y al mismo tiempo es una categoría universal de la experiencia y la vida social. Acordando con la idea de que los rituales exponen y potencian elementos que ya son comunes en la sociedad (Peirano, 2001), el enfoque etnográfico del ritual que guía el estudio de visitas y residencias se orienta a explorar algunos de los modos de representar el tiempo en la sociedad hispano colonial, sin perder de vista que ellas mismas comportaban experiencias y registros del tiempo singulares. ${ }^{9}$ Si bien son pocos los trabajos que avanzaron en estudiar estos procedimientos en sus aspectos simbólicos y rituales, también han revelado que sus alcances e implicancias trascendían a los declamados objetivos de controlar y mejorar las instituciones, y muchas veces ni siquiera los conseguían 
cumplimentar. En un sistema político en que el rey, siendo fuente de poder y legislación, se hallaba físicamente ausente, esta clase de eventos por el carácter ritualizado que adoptaban formaban parte de los instrumentos simbólicos de que disponía la Corona para reafirmar su autoridad sobre los lejanos dominios americanos y aportar a la construcción y reproducción del orden colonial. La conceptualización de estos acontecimientos como rituales ha permitido comprender la significación que asumían en la dinámica política local desde la perspectiva de las sociedades locales así como desde los intereses del poder central. (Guevara-Gil \& Salomon, 1994; Herzog, 2000; Smietniansky, 2013). El estudio del tiempo que aquí presentamos busca profundizar esta línea de investigación y aportar al conocimiento de una faceta poco explorada de estas instituciones.

\section{Las coordenadas del relato: tiempo y espacio ritual}

En cumplimiento de la legislación, las residencias se sustanciaban en un plazo de sesenta días. En el caso de los juicios instruidos a los gobernadores del Tucumán, dado ese límite temporal y la extensión de la gobernación, el juez superior de residencia se establecía en una ciudad y nombraba jueces subdelegados para que administrasen el proceso en el resto de las seis jurisdicciones. La transcripción de las preguntas y de los testimonios, las notificaciones, los informes relativos al estado de la cárcel y los predios de gobierno así como a los papeles del cabildo, fueron acrecentando un expediente que llegó a las 7000 fojas. Los tiempos de la residencia estaban pautados; entre la convocatoria inicial y el cierre marcado por la sentencia se distinguen dos fases centrales: la pesquisa secreta y la pesquisa pública. El plazo de dos meses comenzaba a correr desde el momento en que se publicaba el pregón que informaba a la población el inicio y el objeto del juicio. La preocupación porque esa apertura se desarrollara paralelamente en todas las ciudades se advierte en los dichos del juez de la residencia a Tineo, Baltazar Azebey. Éste argumentaba que resultaba "incompatible que a un mismo tiempo pueda estar en las dilatadas ciudades que se hayan comprehendidas en esta jurisdicción” y ordenaba que todos los jueces publicasen el pregón el 22 de enero de $1764 .^{10}$ Aunque, los preparativos legales del juicio se iniciaron varios meses antes.

A fines de noviembre de 1763 fue recibido por el cabildo salteńo, ante el cual presentó la cédula del Rey, una provisión de la Audiencia de Charcas y un despacho del Virrey que confirmaba su comisión. Azebey se estableció en Salta, que en ese entonces era capital de la gobernación, y remitió a cada ciudad una copia de la cédula real que habilitaba el proceso y del edicto con las indicaciones sobre el modo de instruirlo. A su vez, cada juez subdelegado se ocupó de efectuar la publicación en la plaza pública de la respectiva ciudad y de despachar la misiva a 
las capillas y parajes usuales en que se informaba a los habitantes de las novedades. Esta apertura se acompañaba del sonido de la caja de guerra y, en varios casos, se destacó que la misma tuvo lugar por la mañana. El expediente de Córdoba informa que en el partido de Ischillín la publicación se realizó "en concurso y hora de la misa mayor" y que en el de Tulumba tuvo lugar "en concurso de gente en la puerta mayor de la capilla parroquia de este partido". ${ }^{11}$ En el contexto de una sociedad donde política y religión no definían esferas autónomas, la residencia tomaba prestado, además de los espacios públicos acostumbrados, los tiempos estipulados por el calendario religioso, sirviéndose de la convocatoria social que éstos suponían para comunicar a través de esos canales preestablecidos el pronto inicio del proceso inquisitivo.

Así como en esos dos meses los vecinos de las ciudades asumían nuevos roles - jueces, testigos, demandantes, imputados o asistentes de los magistrados algunos lugares también redefinían su significación. Los edificios del cabildo, la morada de algún vecino importante o aún la casa en que residía el propio juez se transformaban temporalmente en el juzgado de residencia, la audiencia o el estrado en donde comparecían los participantes del proceso. El uso de estos términos para referir lugares, que ordinariamente estaban destinados a otras actividades o fines, da cuenta de la resignificación del espacio que el proceso conllevaba.

Tiempos, comisiones, espacios, roles, demandas, defensas y testimonios tenían fecha de caducidad. A excepción del registro escrito que se producía mientras el juicio avanzaba, todo en la residencia era perecedero. La circulación de misivas al comienzo y al final del juicio constituye una metáfora de ese tiempo efímero. La remisión de la cédula real y demás instrucciones desde Salta, situada al norte de la jurisdicción, hacia el resto de las ciudades señalaba el espacio que quedaba comprendido dentro de la indagatoria, marcando los límites de la gobernación del Tucumán. Esa suerte de apertura que reflejaba el envío paralelo de la documentación se contrapuso con la última etapa en que los funcionarios subdelegados remitieron al juez todos los autos elaborados durante el proceso en cada ciudad. De esa manera, mientras en un comienzo el espacio parecía abrirse o expandirse, en el final el mismo se vio replegado cuando esos manuscritos, ahora acrecentados, retornaron al punto de origen. Tiempo y espacio se constituían mutuamente: la gobernación cobraba cuerpo como una unidad y esto se reflejaba $y$, en parte, se lograba a través de unificar los tiempos de las ciudades.

En comparación con ese panorama, se acentúan las particularidades de la dimensión temporal de la visita. La visita de Luján de Vargas a los indios encomendados del Tucumán ocupó un total de dos años y la cédula que otorgaba la comisión no imponía un plazo a su realización. ${ }^{12}$ El visitador no nombró 
subdelegados sino que él mismo se encargó de instruir el proceso en cada una de las ciudades. Por tanto, si bien en todas se reprodujo la misma estructura de fases - publicación del pregón, toma de testimonios, imputación de cargos, defensa, sentencia - ésa no se desarrolló de manera paralela, sino en forma secuencial. Cada ciudad constituyó una posta en el itinerario que siguió Luján de Vargas: Córdoba, La Rioja, Catamarca, Santiago del Estero, San Miguel de Tucumán, Salta y Jujuy delinearon su recorrido. Era aquí el paso del visitador y no la circulación de escritos lo que iba señalizando el territorio de la jurisdicción tucumana. A su vez, podemos conjeturar que los vecinos de la ciudad próxima a ser visitada estarían expectantes ante la llegada del juez y atentos a las noticias que circulasen desde las ciudades que éste ya hubiera atravesado. Frente a una experiencia de sincronicidad basada en el conocimiento de que en otras ciudades estaba teniendo lugar el mismo acontecimiento (la residencia), en el contexto de la visita, la relación entre las mismas asumía un carácter diacrónico o de contigüidad. La residencia como proceso enfatiza las relaciones paradigmáticas entre las ciudades, mientras que en la visita éstas se sitúan en el eje del sintagma.

$\mathrm{Si}$, por un momento, dejamos de tratar a los documentos sólo como "fuentes" y nos aproximamos a esa mirada que propone Stoler (2002) bajo la expresión "siguiendo la corriente del archivo", veremos que la manera de organizar cada uno de los expedientes también ofrece pistas en el estudio del tiempo. El expediente de la residencia está organizado por ciudad y, al interior de cada una de ellas, por oficio público residenciado. Los testigos en cada ciudad respondieron a un cuestionario de más de cien preguntas que estaba subdividido de acuerdo a los diferentes cargos de gobierno - alcaldes, mayordomos, escribanos, etc. — y sus respuestas fueron luego desagregadas y reagrupadas en función de los mismos. El testimonio oral de un sujeto individual no se trasladaba a la escritura como una totalidad indivisa, sino que era fraccionado. En ese sentido, la edición que se hizo de todos los autos obrados en el marco de la residencia a Tineo no reproduce exactamente cómo se fue desarrollando el juicio, sino que recrea de forma escrita la estructura política local. De esa manera, también el registro escrito imprime una mirada más sincrónica antes que procesual. El expediente de la visita, por su parte, también está organizado por ciudad aunque aquí la secuencia de ciudades reproduce el itinerario seguido por el visitador. Al interior de cada jurisdicción vemos a Luján de Vargas tratar caso por caso: interrogar a un encomendero y sus indios encomendados, dar lugar a la defensa y dictar sentencia, y luego comenzar, bajo el mismo formato, la indagación de una nueva encomienda. Según consta por las fechas, la secuencia de casos tratados reproduce el curso del visitador en la ciudad. Al llegar a cada ciudad ordenaba a los encomenderos que presentasen 
ante él a los indios para proceder con la indagatoria. Los encomenderos tenían dos días para llevar a los indios que estaban en las haciendas y ocho días para el caso de los que estaban más alejados en los pueblos de indios, alterando el curso de las actividades cotidianas.

Cada procedimiento definía también un recorte sobre las realidades locales que investigaba. La gobernación del Tucumán era una región alejada de los centros virreinales de poder y carente de metales preciosos fácilmente accesibles. Así como en el período de exploración y conquistas los feudatarios españoles habían negociado con gran autonomía la adquisición de tierras y encomiendas, en el siglo XVIII nos encontramos a una élite provinciana ya consolidada y cuyos miembros estaban relacionados a través de vínculos económicos, políticos y redes de parentesco que permeaban las instituciones políticas y religiosas. En ese contexto, los cabildos, que no estaban sujetos al cercano control del virrey y la Audiencia, devinieron en instrumento y espacio de disputa entre las facciones locales, y el ejercicio de cargos concejiles en un símbolo de reconocimiento social que marcaba la pertenencia al sector dominante. La residencia era un modo de intervención sobre ese nicho de poder cooptado por las élites coloniales. El accionar de Azebey y la comisión escrita que lo habilitaba, así como el cuestionario de preguntas con que interrogaba a los testigos, indican que las competencias del juez imponían un recorte en términos espaciales (la gobernación del Tucumán), temáticos (el obrar de los funcionarios de gobierno) y temporales (el período correspondiente al mandato del gobernador residenciado).

La visita también delimitó temática y espacialmente la realidad local. El visitador indagó en el sector de la población indígena que se encontraba bajo el sistema de encomiendas, aunque ese criterio homogeneizante no reflejaba el mapa multiétnico que caracterizaba al Tucumán. Aún hasta mediados del siglo XVII esta región presentaba focos de resistencia indígena; el sometimiento de las poblaciones asentadas en los Valles Calchaquíes se produjo recién hacia fines de 1660, y tres décadas antes tuvo lugar la gran rebelión diaguita iniciada en 1630 y reducida en 1643. Además de enajenar sus tierras, los indígenas de estos grupos fueron desnaturalizados y reagrupados no siempre respetando sus pertenencias étnicas en los territorios cercanos a las ciudades espańolas. Muchos fueron entregados en encomienda a los vecinos que participaron en las diferentes campañas; de manera que incluso pasaron a convivir con los grupos originarios de esos espacios. Cuando Luján de Vargas realizó la visita, las sociedades indígenas del Tucumán estaban asistiendo a un proceso de transformación con ritmos y evoluciones desparejas. Diversos factores ligados al contexto local previo a la llegada de los españoles, a las estructuras políticas indígenas preexistentes y a las 
características que revistió el avance conquistador en esa jurisdicción marcaron un proceso de desestructuración de la vida comunal así como al mismo tiempo favorecieron prácticas de resistencia y negociación que aportaron a la pervivencia de algunos grupos nativos. ${ }^{13}$ Las ordenanzas que en 1612 había dictado el visitador Francisco de Alfaro y que casi un siglo después seguían operando como referente normativo sancionaban la conformación de reducciones o pueblos de indios que dispondrían de tierras propias para su subsistencia y de un ámbito propicio para recrear la vida comunitaria. Asimismo, con vistas a suprimir el servicio personal que implicaba un régimen de explotación directa sobre la mano de obra indígena, establecía que los naturales debían pagar un tributo en moneda o especie al encomendero, cinco o diez pesos de acuerdo con la antigüedad de la encomienda. Sin embargo, Luján de Vargas comprobaría la distancia entre la práctica y la norma, advirtiendo que de forma generalizada en toda la provincia éste no se pagaba en plata sino en el servicio personal que incluía tareas múltiples tales como cultivo, viajes para transportar mercaderías, cuidado del ganado, limpieza de la acequia, etc. E incluso, las mujeres también aportaban con la producción de hilado de algodón a la tributación de sus maridos. ${ }^{14}$

A diferencia de la residencia, la visita no tenía una fecha de finalización definida y el visitador tampoco estaba restringido a inquirir sobre acontecimientos situados en un determinado lapso de años. La visita fue motivada por informes pasados que daban cuenta de los sometimientos que los indios padecían a manos de los feudatarios, aunque Luján de Vargas interrogaba la situación presente. En la residencia el tiempo era un criterio que condicionaba y establecía qué contenidos eran importantes y tenían implicaciones jurídicas — se partía de la distinción entre pasado y presente —, mientras que la perspectiva del visitador señala un carácter más bien sincrónico - no obstante, como sabemos, los relatos eran expresivos de los procesos de transformación que estaban atravesando las sociedades indígenas. A la luz del lugar diferencial que, según Alban Bensa (2010), ocupa la temporalidad en la historia y la antropología — una suerte de "materia prima" para la primera y una posición secundaria para segunda - podríamos decir que mientras el juez de residencia oficiaba de historiador, el visitador se acercaba a la tarea del etnógrafo. Incluso, los autos obrados por el visitador resultan más próximos a un "diario de campo" en el sentido de que allí puede leerse día a día, en orden cronológico, las acciones llevadas a cabo por el juez. En el expediente de la residencia, como parte de esa mirada estructural que describimos, los ritmos de su celebración quedaron en gran medida suprimidos en el registro escrito. Si bien, al inscribir cada testimonio, orden del juez, interrogatorio, etc., se señalaba la fecha y el lugar, como decíamos, los papeles producidos en cada ciudad fueron 
en gran medida reorganizados en función de la estructura de los cabildos. Esa perspectiva sobre el pasado se nos ofrece casi a modo de una fotografía. Pero de esto ya nos ocuparemos en el próximo apartado.

\section{La segmentación del pasado: "el tiempo de la residencia"}

Durante el juicio de residencia instruido a Tineo los jueces se encargaron de juzgar la labor de este gobernador y de todos aquellos individuos que ocuparon cargos en los cabildos del Tucumán durante su mandato, entre 1749 y 1754. Los declarantes, los imputados y los magistrados refieren a ese período en términos de "el tiempo de la residencia", "en el tiempo de esta residencia", "en el tiempo de Tineo", "el tiempo de dicho gobernador", entre otras fórmulas similares y asociadas. Estas categorías, a modo de signos indexicales (Peirce, 1955), no comportaban una simple medición general del tiempo sino que asumían un sentido contextual dependiendo de la residencia en que se inscribía su uso: en el caso de Tineo, "el tiempo de la residencia" refería al período 1749-1754, mientras que en la residencia al gobernador Campero (celebrada en 1775-1776) remitía a los años 1764-1769. Cuando les era posible los sujetos residenciados apelaban al criterio temporal para desestimar los cargos que el juez les imputaba. Frente a la acusación de haber estado ausente durante su mandato como alcalde ordinario en el cabildo jujeño, don Pedro de Ereña se defendió señalando que esa ausencia se produjo a principios de 1749 mientras que Tineo asumió como gobernador en junio de 1749. Bajo ese argumento replicaba que la contravención que se le imputaba "no me comprehende su tiempo" y "no es de la jurisdicción de su comisión [la del juez subdelegado Muruaga]". ${ }^{15}$

Este modo de medir el tiempo respondía a los ritmos del ordenamiento jurídico-político: el período en que gobernó cada gobernador y, asociado a ello, el expediente de cada residencia, como metáfora de esa clasificación, segmentaban el fluir continuo de la historia. También cabe agregar que si, por un lado, aquellas categorías definían los marcos temporales - el inicio y el final — de un conjunto de eventos pasados, por otro lado, los sucesos relatados por los declarantes actuaban caracterizando y particularizando ese recorte de la historia, ese tiempo. En los testimonios referidos a la política militar, "el tiempo de Tineo" señalaba una nueva etapa caracterizada por la paz y el orden logrado en la provincia. El vecino jujeño Don Miguel Pacheco de Melo comparaba una etapa previa en que las haciendas y los caminos eran inseguros debido a los robos, muertes y asaltos, en oposición a "la paz y tranquilidad" que la provincia conoció "desde dicho gobierno". ${ }^{16}$ Incluso, en esta clase de declaraciones, el gobierno de Tineo, ese "tiempo de la residencia", antes que definir un período de años operaba como un 
clivaje que distinguía un antes y un después. Los usos de esa categoría enfatizaban una noción de linealidad o progresión en tanto se registraban intervalos de tiempo pasados que podían colocarse secuencialmente y distinguirse unos de otros. Siguiendo la distinción de Valeri (1990), si por un lado, esto sugiere relaciones de carácter sintagmático, por otra parte, los tiempos de los gobernadores (sus respectivos mandatos) resultaban comparados y en ese sentido se vinculaban como elementos análogos de un mismo paradigma.

A ello cabe agregar que en el contexto de la residencia la idea de un tiempo que avanza progresivamente se combina con la regularidad propia del funcionamiento de las instituciones políticas que imponen su reproducción a pesar de la existencia transitoria de los individuos que las integran. En los expedientes resultantes constan quiénes ejercieron cargos en el cabildo de cada ciudad y por cuáles períodos. Por ejemplo, en el caso de los alcaldes que eran elegidos anualmente por los miembros del cabildo, el juez debía tomar conocimiento de los ocupantes de este oficio en cada uno de los ańos contenidos en el "tiempo de la residencia", para lo cual elaboraba una lista que informaba año y cargo. Por otro lado, ese registro de carácter progresivo también daba cuenta de la regularidad y la permanencia del cabildo en su estructura corporativa. La distinción entre los cuerpos sociales y políticos y sus miembros - con tiempos y transcendencias diferentes - se expresaba con claridad en una sociedad donde la familia, la ciudad, el reino, el imperio, así como cualquier tipo de agrupamiento social, eran conceptualizados bajo la metáfora organicista del cuerpo (Agüero, 2007; Kantorowicz, 1985). De hecho, el cabildo era cabeza de la ciudad de igual manera que los alcaldes ordinarios eran la cabeza del cabildo. El estudio del tiempo en el contexto de esta institución ha permitido distinguir el manejo de un tiempo regular propio del calendario anual; el carácter temporario y alternante de sus miembros; y, la valoración y construcción de la perpetuidad de ese cuerpo de gobierno. ${ }^{17}$

Los testimonios registrados en el expediente de la residencia y producidos en diálogo con el esquema provisto por el juez ayudan a aproximarnos a las perspectivas de los vecinos sobre ese espacio político. En ocasiones, los testigos destacaban el obrar — bueno o malo — de algún funcionario en particular, pero en muchas otras declaraban sobre el conjunto de los ocupantes de un determinado oficio sin hacer distinción de individuos y de años. Por ejemplo, sobre las preguntas relativas a los alcaldes en La Rioja, don Agustín Mercado declaró que "han administrado justicia y obedecido las cartas provisiones reales", 18 y otro vecino manifestó que "han guardado y cumplido con las leyes". En San Miguel de Tucumán Juan de Reto, por su parte, sostuvo que "los alcaldes y regidores elegían a sus allegados, y parciales". ${ }^{19}$ Esas respuestas comprehenden todos los 
años correspondientes al período de Tineo y a todos aquellos que ejercieron el oficio de alcalde. En estos casos, el modo corporativo o colectivo de referenciar a los funcionarios resultaba enfatizado por sobre la coyuntura y la individualidad de los ocupantes temporarios de ese cargo. ${ }^{20}$ La mirada estructural implicada en los cuestionarios y la organización del expediente encontraba su contrapartida en esta clase de respuesta.

Indagamos un poco más la expresión "tiempo de la residencia” y advertimos que su uso no revestía un sentido unívoco. En muchas declaraciones parecía tratarse de un tiempo lejano sobre el cual los recuerdos se presentaban — por los mismos testigos - como imprecisos y de veracidad incierta. En La Rioja, el juez tomó testimonio a 16 vecinos. Al interrogarlos sobre la conducta de los alcaldes ordinarios, 3 recurrieron a las típicas fórmulas "no sabe", "no recuerda" o "no tiene presente" en un $50 \%$ de las preguntas, 7 manifestaron desconocimiento en un $75 \%$ de las mismas, 4 los hicieron en casi un $90 \%$ y 3 en un $65 \%$. El desconocimiento fundado en ese paso del tiempo era frecuente en los testimonios y constituía un modo a través del cual las facciones locales intentaron contrarrestar el interés regio por conocer e intervenir en esos espacios de poder. Pero en otras ocasiones los declarantes se explayaban en sus testimonios y describían con detalle acontecimientos, fechas precisas, sujetos participantes, lugares, etc., y allí "el tiempo de la residencia” resultaba más bien cercano, o al menos lo suficiente para guardarlo en la memoria. Especialmente recurrían a sus experiencias personales cuando éstas aportaban a engrandecer su propia figura. Por ejemplo, esto es notorio en Salta y Jujuy cuando los testigos al responder sobre el obrar del Tineo narraban su propia participación en la guerra de la frontera chaqueña junto al gobernador. El vecino de Salta don Martín de Iturríos, como "testigo de vista" y participante de en sucesivas campañas al Chaco, relató las medidas tomadas por el gobernador como parte de su política ofensiva contra los indios. ${ }^{21}$

\section{La visita: el tiempo como un presente continuo}

En 1690 por cédula real se comisionó al oidor de la Audiencia de Charcas Antonio Martínez Luján de Vargas la realización de una visita a los indios encomendados del Tucumán. En agosto de 1692 y ante la Audiencia, fue recibida y obedecida la cédula y se lo invistió en el oficio de visitador. Luego de su paso por Córdoba, siguió camino hacia La Rioja y el 31 de mayo de 1693 en la plaza de dicha ciudad se publicó el pregón que anunciaba a toda la población el inminente inicio del proceso. Bajo las fórmulas acostumbradas el escribano registró por escrito ese momento, indicando 1) la fecha y el lugar de realización; 2) la presencia de una audiencia pública; 3) el carácter audible de la proclamación; 4) el mensaje de la 
proclama - alude a la cédula real y al deber de los encomenderos de presentar a los indios encomendados ante el visitador; y 5) las autoridades presentes y los testigos. El pregón, por un lado, informaba el modo de realización de la visita y la autoridad comisionada Luján de Vargas; y por otro lado, su misma publicación señalaba el comienzo de la pesquisa. El carácter ritual resultaba económico a los efectos de transmitir un mensaje a toda la población (de mayoría analfabeta), a pesar de que la convocatoria hacía partícipes sólo a los encomenderos y a los indios encomendados. También como un ritual, era inclusivo y al mismo tiempo delimitaba la pertenencia a un determinado sector de la población.

En la instancia testimonial, el cuestionario de cinco preguntas examinaba una serie de aspectos de las relaciones entre indios y encomenderos, en vistas de evaluar si los feudatarios cumplían con las obligaciones que imponía su cargo. ${ }^{22}$ Por un lado, a excepción de la última pregunta, todas están formuladas en tiempo presente, es decir, el oidor buscaba reconocer la situación de la población indígena en ese momento, como un etnógrafo en el "aquí y ahora”. Por otro lado, la asociación entre intervalos temporales y actividades que tenían un desarrollo periódico sugiere un tiempo de carácter regular y cíclico. La primera pregunta señala ciertos días en particular, "días de fiesta", en los cuales los indios debían asistir a misa e instruirse en la doctrina católica, mientras que en la segunda pregunta la marcación del tiempo en lapsos regulares - "cada semana", "cada mes" - va asociada al "trabajo personal" con que los indios servían a sus encomenderos y al pago que éstos debían sustanciar como retribución.

Los testimonios de indios y encomenderos intercalan relatos en tiempo presente con descripciones de situaciones en tiempo pasado. Uno de los indios pertenecientes a la encomienda de Francisco Barrionuevo "dijo que no tienen tierras seńaladas para sembrar ni capilla donde oír misa que tal vez oyen misa en esta ciudad" y que el "encomendero no les enseńa la doctrina cristiana ni a rezar y así no saben y que está éste que declara como cuando lo trajeron del valle Calchaquí". Cuando le tocó responder a la segunda pregunta, "dijo que no ha pagado tributo a su encomendero en plata ni en otra especie si no es el servicio personal que todo el año le hacen al encomendero", y éste les ha retribuido en "calzones y orgarina de pañete o cordellate" (Boixadós \& Zanolli, 2003: 80). $\mathrm{Al}$ describir el trabajo femenino, informaba que "les dan algodón de tarea para que entre todas tres entreguen dos onzas de hilado cada día” mientras que en pasado refería situaciones en que las mujeres fueron azotadas por no haber cumplido con dicha labor. Para examinar las representaciones de las relaciones entre pasado y presente tampoco debemos perder de vista que la visita era una respuesta frente a una serie de informes previos. Luján de Vargas interrogaba el 
presente, imputaba a los encomenderos los cargos en tiempo pasado y establecía medidas en vistas a remediar las faltas en el futuro. Al leer el expediente nada de esto resulta extrańo; estos posicionamientos frente al pasado se ponen en evidencia cuando los comparamos con la residencia. Mientras el juez de residencia partía de la separación entre pasado y presente, en los diálogos reconstruidos en las fojas de la visita esa distinción no es taxativa. Junto con la continuidad o yuxtaposición entre eventos pasados y presentes, cabe agregar que, en general, no se especifica la duración del lapso de tiempo transcurrido. Es notoria la ausencia de fechas exactas (más aún si lo comparamos con las residencias) y es recurrente el uso de categorías imprecisas como "el tiempo que me ha servido", "todos los años", "algunos años”, pero, ¿cuáles o cuántos años comprendían esas marcaciones temporales? Todo indica que la cualificación numérica no era relevante. ${ }^{23}$

Algunos testimonios permiten aproximarnos a la amplitud temporal de esas expresiones. Joseph Díaz de Oviedo presentó al visitador dos indios de la nación Quilme e indicó que los había recibido en encomienda "en la entrada que hicieron al valle de Calchaquí” (Boixadós \& Zanolli, 2003: 156). Frente a las acusaciones del indio Francisco, apuntó que éste tenía tierras propias donde sembraba y "donde ha muchos años que viven [con su mujer, Catalina]", y luego especificó "donde vive a más de veinte años con muy buena comodidad" (Boixadós \&Zanolli, 2003: 157). Es decir, las declaraciones del encomendero sobre los cuidados que en ese momento les dispensaba a los indios encomendados y las labores que éstos realizaban formulaban un relato que lo retrotraía dos décadas atrás y un pasado marcado por un acontecimiento específico, su participación en la guerra en la frontera chaqueńa. La ausencia de fechas se compensaba con el registro de eventos puntuales que trazaban el desarrollo de una historia. En otra ocasión, Luján de Vargas acusó a Domingo Nieto Príncipe de no haber asignado tierras a los indios para que tuvieran sus sementeras y el encomendero, en su defensa, alegó que los indios tenían esas tierras "de más de veinte años a esta parte" y que las mismas fueron dadas por su padre, el capitán Miguel Nieto Príncipe, a quien él sucedió como encomendero "en segunda vida", es decir, como su hijo (Boixadós \& Zanolli, 2003: 181). Como a la mayor parte de los encomenderos, el visitador también le imputó haber tenido a los indios bajo la modalidad de servicio personal y no haberles pagado el jornal correspondiente, además de enfatizar que ese régimen estaba prohibido. Domingo Nieto respondió que los indios fueron concedidos por el gobernador don Mercado y Villacorta para el cultivo de sementeras, que en ese trabajo los ocupó su padre y que en su visita el gobernador don José de Garro destacó el buen tratamiento que los mismos recibían. De esta manera el encomendero se excusaba alegando la continuidad de una situación aunque sin 
necesariamente apelar a una datación cronológica exacta. En el contexto de su declaración, la mención a los "más de veinte años" luego deja lugar a la narración de una historia donde abundan las referencias a personajes y situaciones particulares ligados al ordenamiento político y también al parentesco: la época en que su padre era el encomendero, la gobernación de Mercado y Villacorta (1655-1660 y 16641670) y la visita de José de Garro (1678). Puede advertirse que este uso temporal de los mandatos de los gobernadores se corresponde con la segmentación básica del tiempo que organizaba los testimonios de la residencia. Aunque en la visita esa referencia temporal no era impuesta por el mismo procedimiento inquisitivo sino que aparecía combinada con otras categorías temporales en los testimonios.

Cuando fue el turno de la defensa de Francisco Moreno Maldonado, la "costumbre" ocupó un papel central para indicar que las prácticas que el visitador le objetaba eran ya "costumbre" al momento en que él se invistió en el cargo encomendero. En respuesta a la acusación de haber cobrado el tributo en hilado femenino, "dijo que cuando entró este declarante a la dicha encomienda halló en costumbre que los indios pagaban en el hilado de sus mujeres" (Boixadós \& Zanolli, 2003: 191). Sobre la falta de ornamentos en la iglesia del pueblo de Famatina indicó que "desde que entré a ser encomendero hallé dispuesto y en uso" que el cura doctrinante los llevaba consigo a cada pueblo al que asistía para dar misa. También declaró que era costumbre que hubiera mayordomos en los pueblos de indios y para ello se remontó al gobierno de Mercado y Villacorta, al momento en que él ingresó como encomendero y a la visita de Garro quien convalidó la situación. La apelación a la "costumbre" se inscribía en el marco de un sistema jurídico casuístico y flexible, donde la ley, la costumbre y la doctrina de los autores -las tres fuentes del derecho- no actuaban de manera uniforme y exclusiva. Las costumbres locales en el contexto de un Nuevo Mundo caracterizado por su diversidad de pueblos, culturas, lenguas y geografías, tenían tanta fuerza como las normas jurídicas generales impartidas desde los órganos centrales (Tau Anzoátegui, 2001). Por otra parte, si bien "costumbre" no tiene un referente temporal explícito, ello no invalida su "función temporalizadora" (Fabian, 1983); incluso, en las fuentes es común encontrarla asociada a otras expresiones tales como "costumbre inmemorial" y "tiempo inmemorial” y en oposición a vocablos que informan el cambio, como "innovar". La apelación que los declarantes hacían al término "costumbre" enfatizaba la permanencia, el no-cambio. Incluso, la referencia a la experiencia personal y a eventos pasados funcionaba para confirmar la existencia para ese entonces de dicha "costumbre". ${ }^{24}$

En los autos de la visita, otros operadores temporales aparecen con recurrencia en el contexto de relatos que describen la dinámica del trabajo y la conducta abusiva 
de los encomenderos sobre los indios. Categorías tales como "todos los años" o "algunos años" eran puestas en relación con las prestaciones y contraprestaciones que vinculaban a ambas partes. "El tiempo que me ha servido" sintetiza esta idea: el tiempo se define a partir de la duración de la relación de servicio de personal. Por otra parte, "tiempos de siembra", "días de fiesta”, "días de oír misa", entre otras expresiones, eran categorías temporales que cobraban sentido en el marco de la organización de la producción agrícola y el calendario religioso. En este caso, el tiempo aparece definido por las actividades que en ese momento se estuvieren desarrollando en tanto una fase de un ciclo más amplio. No obstante, la segmentación en días, meses y años constituye un marco referencial muy importante en las declaraciones, especialmente como un modo de medición de la cantidad de trabajo y su retribución. Uno de los indios de la encomienda de don Diego de Herrera refirió que "suelen venir a oír misa tal vez a esta ciudad algunos domingos porque los más [...] está en dicha hacienda trabajando en la viña”, y también manifestó que Isabel, una de las indias, servía de cocinera a la esposa del encomendero y ésta "por su trabajo le da de vestir al año una manta y dos varas de bayeta” (Boixadós \& Zanolli, 2003: 138).

La apelación conjunta a diferentes modos de registrar y representar el tiempo aparece en relatos que focalizan distintos aspectos de la vida social. El siguiente testimonio combina una concepción cuantificable en intervalos regulares (días, meses, años) con un régimen temporal basado en el desarrollo periódico de actividades productivas concretas y las características que adoptaba la interacción entre indios y encomenderos. Se trata de la declaración de Francisco Durán de Velasteguy sobre los sucesos que presenció cuando visitó la estancia de Sañogasta, propiedad de Gregorio Brizuela:

generalmente ha visto el maltratamiento que les hace con todo rigor y aspereza peor que si fuesen sus esclavos porque el régimen ordinario que tiene y vio este testigo el que los indios que le asisten y sirven se levantan a las cuatro de la mañana y van a traer leña y al que falta en algo le da de rebencazos y que en lo restante del día anda en un caballo el susodicho registrando lo que trabajan los dichos indios y por cualquier descuido les da con un rebenque que de ordinario trae en la mano... (Boixadós \& Zanolli, 2003: 238).

Francisco describe un "régimen ordinario", un día que, como todos los días que le han precedido y que le seguirán, se constituye a partir de una misma secuencia de actividades. Esta mirada que insinúa un tiempo regular y cíclico se enfatiza a través de conjugar los verbos en presente para describir la vida en la hacienda, oponiéndose al tiempo de su propia visita a la misma que no duda en colocar en pasado: un acontecimiento que ha concluido sobre el trasfondo de 
un orden que no deja de replicarse diariamente. ${ }^{25}$ Por otra parte, al describir el inicio del día, apela tanto a la marcación horaria como a la primera labor que realizan los indios encomendados. El "restante del día" es tiempo de servicio y de trabajo indígena mientras el encomendero ejerce un control coactivo montando su caballo. En este caso, se trata de un tiempo caracterizado por una actividad constante y franqueado por el castigo físico impuesto por el feudatario, lo que, a su vez, devuelve la imagen de un régimen ordinario marcado por la violencia.

\section{Categorías temporales en uso}

A la par de la regularidad del ciclo agrícola operaba el ritmo también reglamentado de las instituciones políticas, y, a veces, entrababan en tensión. En la visita de Luján de Vargas, el encomendero Gil Bazán se excusó de no poder asistir a la siembra alegando "estar impedido y embarazado con mi oficio de regidor” (Boixadós \& Zanolli, 2003: 171). En la residencia a Tineo y como parte de su descargo, don Diego de Aráoz, igual que otros funcionarios capitulares, argumentó que estaba permitido que "los regidores salgan a ver sus haciendas [ausentándose de sus funciones de gobierno], y al reparo de ellas para manutención de sus familias por no tener salario alguno por el oficio". ${ }^{26}$ En ese mismo juicio, Tineo presentó documentación variada sobre sus acciones militares y la resistencia que ofrecieron los vecinos de varias ciudades a participar de la guerra contra los indios de la frontera chaqueña. Allí sostiene que:

oigo quejarse que en el tiempo que se hacen las corridas les embarazan sus siembras, cosechas y negocios, pero es cosa visible oír que en los doce meses del año no hay tiempo adecuado para salir porque enero, febrero, marzo, abril y mayo son lluvias y pantanos los que embarazan, junio y julio las siembras, agosto septiembre octubre noviembre y diciembre debilidad de las caballadas y cosechas; vuelven a entrar las lluvias con que no hay tiempo acomodado como si los indios para venirnos a invadir tuvieran determinado tiempo... ${ }^{27}$

El texto, que pertenece a un informe de guerra escrito por Tineo mientras estaba al mando de la gobernación del Tucumán y que está transcripto en el expediente de la residencia, expresa cómo los tiempos de la guerra, el trabajo agrícola y la ecología parecieran haber entrado 'estratégicamente' en conflicto. El estilo burlón no invalida la muestra que su autor nos brinda sobre la coexistencia de varios tiempos. Hay un "tiempo en que se hacen las corridas" y que Tineo irónicamente decía no poder ubicar en los doce meses del año por cuanto los vecinos siempre tenían una excusa para evitar participar. Ese tiempo no-adecuado se segmenta entre unos meses que "son lluvias y pantanos", otros "las siembras" y 
un tercer grupo de "debilidad de las caballadas y cosechas". Por otra parte, si bien el tiempo de la guerra no era regular como el tiempo ecológico y productivo, sí al menos más previsible que el 'no-determinado' de las invasiones indígenas. El ciclo nuevamente volvía a comenzar con el inicio de cada año. En este punto no importa si de hecho la motivación de los vecinos para apelar a esos argumentos respondía, como decía Tineo, a no querer participar de la guerra, algo que está fuera de nuestro alcance saber con estos materiales. Lo que sí resulta relevante es, por un lado, la manera en que el año era segmentado en función de dichas actividades, y las implicancias del trabajo agrícola y los ciclos ecológicos en esa temporalización del orden social. Tineo juega entre el marco y clasificación provista por el calendario y la temporalidad definida a partir de las actividades concretas. Por otra parte, la alusión a las poblaciones indígenas aún no conquistadas plantea el interrogante de cómo, bajo la perspectiva del gobernador, se contraponían los tiempos de su propia sociedad y los tiempos de ese otro. La imagen del otro pareciera haberse construido por medio de la ausencia del ordenamiento temporal que caracterizaba al nosotros. Si bien superpuestos, los tiempos del nosotros se describen formando parte de un orden regular y previsible; a los bárbaros se les niega esta condición.

Vale la pena reproducir un tramo más de su reclamo:

y no falta quien diga que en mi tiempo se destruye y empobrece la Provincia. Ésta sí que es una abierta ingratitud contra Dios, pues en ningún tiempo se vio en más opulencia ni experimentaron el sosiego que hoy, las fronteras pobladas, cultivadas las haciendas de ellas con muchos ganados... ${ }^{28}$

Aquí era su tiempo el que estaba en discusión. Pero éste no era el tiempo cíclico de lluvias, cosecha y siembra, sino que era el tiempo en que él ejerció - en ese entonces, estaba ejerciendo - como gobernador. Este tiempo no se reproducía año a año, era único, diferente a los tiempos de otros gobernadores. Los mandatos de los gobernadores en cuanto períodos políticos (aunque no siempre de igual duración) eran unidades homólogas y por tanto comparables, pero los hechos allí sucedidos eran únicos. En pocas líneas, los dichos de Tineo ofrecen algunas de las categorías temporales y modos de registrar el tiempo que venimos explorando y, más aún, dan cuenta de la manera en que estas expresiones operaban temporizando el mundo social y las experiencias de vida de los sujetos. Si bien resulta anacrónico trasladar nuestras modernas concepciones de política, economía y religión a la sociedad hispano colonial (Agüero, 2007), por otro lado, las representaciones del tiempo sugieren distinciones en esa dirección, como lo expresaba el mismo Tineo. Aunque aquí esa distinción no es espacial o en términos de campos, sino temporal (Palmeira, 2001). 
En otro orden del análisis, también advertimos que las categorías temporales no operaban todas de la misma manera. Expresiones tales como "mi tiempo" o "el tiempo de la residencia" señalaban un período del que podían establecerse fechas de inicio y finalización (que los actores explicitaban, de ser necesario), pero además ese significado revestía un carácter indexical puesto que se constituía a partir del contexto en que era enunciado (Peirce, 1955). Cuando se utilizaba "el tiempo de la residencia" no remitía a todas las residencias sino que operaba particularizando, refería al recorte temporal de la residencia que se estaba llevando a cabo. Igual lógica sigue la frase "mi tiempo", sólo que en este caso el tiempo se puso en relación con quien enunciaba la frase, el gobernador Tineo. Otras categorías como "tiempo de siembra", "tiempo de oír misa", etc., realizaban su sentido independientemente del contexto. Definían un momento específico dentro de un régimen regular y cíclico de actividades. A su vez, en el contexto de la visita, esas expresiones fueron puestas en relación con otras - por ej. "algunos años" y "el tiempo que me ha servido" — que, si bien buscaban definir un lapso temporal pasado, lo hacían de forma imprecisa. Por su parte, la noción de "costumbre", muy común en las fuentes coloniales, operaba legitimando una práctica a través de enfatizar su permanencia a lo largo del tiempo, una suerte de 'siempre ha sido así. Vista la apelación conjunta a estas diversas expresiones en el contexto de la visita, sugerimos que las referencias temporales 'provenientes' del ordenamiento de las instituciones de gobierno y que con más claridad aparecen en la residencia - por ej., el mandato de un gobernador - contribuían a señalar acontecimientos o situar períodos de tiempo pasados que de otra forma se perderían bajo las representaciones de regularidad y de continuidad entre presente y pasado. ${ }^{29}$

\section{Reflexiones finales: ¿̨un orden social temporalizado?}

Usualmente, en cualquier pueblo, existen diferentes imágenes del pasado que entran en conflicto: unas pueden legitimar la transformación y otras la continuidad; unas lo conciben en términos de proceso, un 'llegar a ser', y otras como duración y permanencia (Valeri, 1990). Los materiales que presentamos permiten acceder a algunas de las perspectivas sobre el tiempo y el pasado en la sociedad hispano colonial, develando un panorama heterogéneo y complejo que, por momentos, obstaculiza hacer foco. Cuando en el análisis de los documentos dejamos de mirar sólo las categorías temporales, el tiempo aparece simplemente en todas partes. Esta investigación se depara con la dificultad de realizar un recorte sobre un tema omnipresente en los materiales etnográficos; afinar las preguntas y el camino analítico puede considerarse uno de sus avances parciales. 
La mirada colocada sobre las categorías y el registro del tiempo fue señalando una nueva problemática: las representaciones temporalizadas del mundo social que nos ocupa. Si categorías tales como costumbre o tiempo inmemorial ofrecen la imagen de un orden social estable y la pretensión del no-cambio, otras como tiempo de siembra o tiempo de la residencia expresan una sociedad dinámica, en constante proceso de transformación, sean estos cambios parte de un ciclo regular o acontecimientos históricos e irrepetibles. Entonces, ¿cómo se articulaban nociones que enfatizaban la permanencia y a-historicidad y aquéllas que expresaban un ordenamiento cíclico y procesual? Por otra parte, vista la relación entre el tiempo ritual de visitas y residencias, la delimitación de las jurisdicciones políticas y las competencias judiciales, surge el interrogante sobre cómo el tiempo operaba en la definición de la pertenencia a una ciudad, a la gobernación o al mismo cuerpo de la monarquía.

La relación entre tiempo y poder constituye otro aspecto en el cual profundizar. Visitas y residencias al intervenir en las sociedades e instituciones locales imponían los tiempos regios: ¿qué efectos posteriores tiene la experiencia de coetaneidad (obligada) de la residencia, que recreaba, aunque sea por un breve período, la unidad de la gobernación? Una vez sustanciadas, ¿devinieron las visitas y residencias examinadas en acontecimientos que actuaron como referentes temporales del pasado?

Ambas instituciones configuran un campo privilegiado para explorar la doble perspectiva - local y regia - que reclama la historiografía sobre América colonial. Los expedientes pueden ser leídos a "contrapelo" tratando de reconstruir las historias locales según fueron contadas por sus protagonistas o testigos y devolviéndole la temporalidad del ritual que la escritura ha trastocado. Pero, por otro lado, también podemos seguir su lógica de edición, organización y clasificación. La heterogeneidad de la sociedad del Tucumán colonial resultó compartimentada, clasificada, sistematizada en el cuerpo de extensos expedientes que enviados a la Audiencia o al Consejo de Indias serían un potencial instrumento de conocimiento y control sobre los dominios australes del Imperio español. Leídos e interrogados en esa dirección, definen una vía para aproximarnos a la perspectiva histórica y temporal del Estado colonial.

Finalmente, los expedientes se prestan a profundizar el examen sobre cómo los protagonistas de este mundo social temporalizaban el objeto de sus discursos y las implicaciones que esto asumía en la construcción del otro en el contexto de una sociedad jerárquica, multiétnica y dinámica. La distinción de Tineo entre el tiempo de la civilización y la ausencia de orden temporal en los bárbaros, así como la doble temporalidad que ofrece el testimonio de Francisco Durán de 
Velasteguy (su tiempo y el tiempo que transcurre en la hacienda de Sañogasta) insinúan caminos posibles para explorar cómo el tiempo operaba definiendo y clasificando a la otredad (las otredades) de la sociedad colonial.

Recebido em: 25/02/2016

Aprovado em: 30/11/2017

Silvina Smietniansky es doctora en antropología por la Universidad de Buenos Aires e investigadora del Consejo Nacional de Investigaciones Científicas y Técnicas y del Centro de Estudios en Historia, Cultura y Memoria (Universidad Nacional de Quilmes). Áreas de interés: antropología de los rituales, antropología histórica e Hispano-América colonial. Autora de Ritual, tiempo y poder: una aproximación antropológica a las instituciones del gobierno colonial (Gobernación del Tucumán, siglos XVII y XVIII) (Prohistoria, 2013). E-mail: silvismiet@gmail.com

\section{Notas}

1. La escritura de este artículo se inició en el transcurso del proyecto de investigación postdoctoral que con apoyo del CNPq llevé a cabo en el marco del PPGAS del Departamento de Antropología de la Universidad de Brasilia, entre 2013 y 2015. Agradezco al DAN por facilitarme las condiciones para el elaboración de este trabajo y a Mariza Peirano por su orientación durante dicha estancia y sus interesantes comentarios a una primera versión del mismo.

2. En el recorrido bibliográfico seguimos, en parte, la lectura crítica trazada por Nancy Munn (1992).

3. La literatura sobre el tema es extensa. Para una revisión crítica sobre los estudios antropológicos del tiempo, véase Munn (1992) y Gell (1992). El número 43(4) de Current Anthropology: (Special Issue Repertoires of Timekeeping in Anthropology) fue especialmente dedicado a trabajos etnográficos sobre los formas de registro del tiempo.

4. Además de las referencias citadas previamente, cabe señalar el trabajo de Irving Hallowel (1955) sobre las "orientaciones temporales" que registró entre los Saulteaux como ejemplo de este abordaje. Por otra parte, en su estudio sociológico más general sobre el tiempo, Norbert Elias apunta que frente a la objetivación que comúnmente hacemos del tiempo y que se ve reforzada por su expresión sustantivada, la forma verbal de este concepto - ej. timing en inglés - "pone de relieve que en la determinación o 
sincronización del tiempo se trata de una actividad humana con fines definidos y no sólo de una relación, sino de un poner-en-relación. La cuestión es: ¿quién, en este caso, relaciona qué, con qué y con qué fin?” (2010:67).

5. En este punto, su crítica se dirige a Evans-Pritchard y Fortes, en particular, a la idea de que las "sociedades tradicionales" conciben el pasado únicamente como una representación de una estructura social que no se modifica ("tiempo estructural"), lo que legitima el presente y refuerza una tendencia al no-cambio (Valeri, 1990:119).

6. El trabajo de Mariluz Urquijo (1952), con un énfasis en la historia institucional, es un referente clásico sobre las residencias en América. Para un estado de la cuestión véase Herzog (2000) y Smietniansky (2013).

7. La institución de la encomienda implicaba la adjudicación de grupos de indios a colonos españoles denominados "encomenderos" que estaban encargados de su cuidado y evangelización y, como contraprestación recibían el tributo indígena. Esta concesión que daba la Corona por los servicios prestados en la conquista no conllevaba el ejercicio de jurisdicción ni la propiedad sobre las tierras. Los naturales mantenían el derecho a conservarlas y labrarlas para su subsistencia. En el Tucumán la práctica quedó bastante alejada de la norma y la explotación de las comunidades nativas adoptó la modalidad de servicio personal que tuvo fuertes implicaciones en la desestructuración de las mismas (Lorandi, 1988). La visita de Luján de Vargas ha sido extensamente estudiada de cara a estos procesos. En general, los trabajos abordaron la situación de la sociedad indígena hacia fines del siglo XVII, los abusos y padecimientos a manos de los encomenderos, el sistema de encomiendas y los alcances desestructuradores del servicio personal, los procesos de continuidad y de cambio en la sociedad colonial, entre otros temas. En su mayor parte se trata de estudios centrados en las jurisdicciones que visitó Luján de Vargas y develan las características que esos procesos asumieron en Santiago del Estero (Farbermarn, 1991, 2002), La Rioja (Boixadós, 2002, 2003), Jujuy (Zanolli, 2003), Salta (Castro Olañeta, 2007), Tucumán (Noli, 2003) y Córdoba (Bixio, 2009; González Navarro, 2009; Iarza, 2009; Grana, 2009); mientras que otros avanzaron en una perspectiva regional y comparativa (Doucet, 1980a, 1980b; Farberman $\&$ Boixadós, 2006, 2009-2010). Este artículo recupera dicha producción como insumo de análisis pero no profundizará esa línea de investigación.

8. Si bien hubo muchas visitas ordenadas por la Corona para el área andina, en la jurisdicción tucumana la única visita general que se conserva (por tanto la más estudiada) es la visita de Luján de Vargas. De la totalidad del expediente, sólo están publicados los autos correspondientes a las jurisdicciones de Jujuy y La Rioja (Boixadós \& Zanolli, 2003) y Córdoba (Bixio, 2009). Con el trasfondo de la literatura académica producida para otras ciudades, este artículo se centra en el caso riojano (cuyo original consta de 400 fojas) y tiene en vistas para futuros trabajos incorporar el examen del resto del itinerario. En cuanto a las residencias, además del caso de Tineo, también hemos examinado la residencia instruida al gobernador don Juan Manuel Fernández Campero en 1775-1776. 
Cabe destacar que son expedientes muy extensos, de 7000 y 3500 fojas, respectivamente. Si bien sería conveniente avanzar en el reconocimiento de otros más tempranos, estudios desarrollados a partir de otras regiones y contextos de Hispanoamérica muestran una misma estructura. Por otra parte, este trabajo presta continuidad con otros.

9. Nuestra aproximación al uso del concepto de ritual en el análisis de las residencias a partir de aportes provenientes de las teorías de Victor Turner, Edmund Leach y Stanley Tambiah se encuentra desarrollada en Smietniansky $(2012,2013)$. Como parte de una investigación en curso, este artículo también presta continuidad con trabajos previos (Smietniansky, 2010, 2013, 2015) centrados en el estudio del tiempo en el contexto de los cabildos coloniales y las residencias.

10. Archivo Histórico Nacional (AHN), Madrid. 1753-1792. Residencia de Juan Martínez de Tineo, gobernador de Tucumán. Consejos, 20374, expediente 1, Pieza 4, f. 17r.

11. AHN, Consejos, 20375, exp. 1, Pieza 8, f. 99r y f. 103r.

12. El visitador inició su viaje desde Charcas en agosto de 1692 y retornó a la misma ciudad en julio de 1694 .

13. El expediente de la visita ha sido una fuente muy importante para el estudio de dichos procesos. Véase nota al pie vi.

14. Como apuntan Farberman y Boixadós (2006), en la práctica coexistían el tributo y el "servicio personal". El primero con mayor preeminencia en los pueblos de indios y el segundo en los casos en que las encomiendas estaban localizadas en las tierras del encomendero.

15. AHN, Consejos, 20375, exp. 1, Pieza 7, f. 169r.

16. AHN, Consejos, 20375, exp. 1, Pieza 7, f. 81r.

17. La idea de perpetuarse y de preservar la identidad a lo largo del tiempo se expresa, por ejemplo, en la alusión corriente que hacían los funcionarios del cabildo al momento de la fundación de la ciudad, para plantear la continuidad entre ese cabildo situado en un "tiempo inmemorial" (la fundación de la reviste un doble carácter, histórico y mítico) y el cabildo del que ellos hacían parte. Los "archivos" y los "libros del cabildo" también constituían índices de esa trascendencia. Por otra parte, el calendario anual que incluía las rutinas de trabajo de los funcionarios y las sesiones semanales del cuerpo, las fiestas religiosas y cívicas, las elecciones anuales, etc., configuraba un tiempo caracterizado por la repetición y la regularidad. Por último, esos atributos se articulaban con la experiencia de aquello que era efímero y alternante: los miembros del cabildo eran las partes temporarias de un cuerpo que permanecía y eran también integrantes de las parcialidades locales que ocupaban alternadamente los cargos de la institución capitular. Estos tiempos aportaban a definir la temporalidad cotidiana y local de las ciudades del Tucumán (Smietniansky, 2010, 2013).

18. AHN, Consejos, 20374, exp. 1, Pieza 4, f. 147r.

19. AHN, Consejos, 20374, exp. 1, Pieza 4, f. 126v.

20. Herzog (2000) encuentra esta misma situación para el caso de Quito. 
21. "Avanzó tierra adentro del fuerte de San Joseph veinte leguas hizo el fuerte de Nuestra Señora del Rosario construyéndolo con gente pagada haciendo allí capilla donde mantuvo capellán y soldados de la cual disposición resultó que quedaron los Indios con temor y en esta ocasión despachó a este declarante con ciento y cincuenta hombres al río Grande tierra de los mataguaios para que los sacase a reducción y a hacer tratador sobre ellos..." (AHN, Consejos, Exp. 20374, Pieza 1, f. 191v-198v).

22. En Boixadós y Zanolli (2003: 69-70), se reproduce el cuestionario:

"1- Primeramente sean preguntados si tienen pueblo o reducción, tierras para sembrar y capilla para oír misa los días de fiesta si la oyen y si se les enseña la doctrina cristiana-

2- Qué cantidad de tributo pagan y en qué especie al encomendero o si le sirven personalmente y en qué forma es el servicio y si en él hay alguna fuerza y apremio o qué cantidad les paga el encomendero cada semana o cada mes por este trabajo señalándoles jornal fijo y si les debe alguna cosa

3- Ítem si las indias pagan tributo o sirven personalmente y si se les paga y cuánto por este servicio y si se les reparte tarea de hilados y si se sirve de los muchachos que no tienen diez y ocho ańos

4- Ítem si son los indios y las indias bien tratados de sus encomenderos o hay azotes y malos tratamientos o prisiones y por qué causas

5- Ítem si el encomendero ha sacado los indios de la encomienda para que trabajen con otras personas o los ha alquilado para algunos viajes"

23. Le Goff observa que en la Edad Media los hombres no eran indiferentes al tiempo sino que el cuadro de referencia de los acontecimientos no eran los números. Informados por el tiempo cristiano de una historia sagrada y significante, en la "mentalidad colectiva" se registra una confusión temporal entre pasado, presente y futuro: "a crença dos homens da Idade Média de que tudo o que é fundamental para a humanidade é contemporâneo [...]. Mentalidade mágica que do passado faz presente porque a trama da história é a eternidade" (1983: 218).

24. Pocock (1987) observa que en el derecho común inglés la apelación a eventos históricos puntuales servía para señalar el carácter inmemorial de una ley, afirmando que en el aquel entonces esa ley existía o, mejor dicho, era preexistente a los acontecimientos referidos.

25. Ese discurso arroja las mismas consecuencias que Fabian señala en relación con "presente etnográfico": "the present tense "freezes" a society at the time of observation; at worst, it contains assumptions about the repetitiveness, predictability, and conservatism primitives" (1983:81).

26. AHN, Consejos, Exp. 20374, Pieza 5, f. 224r.

27. AHN, Consejos, 20374, exp. 1, pieza 1, f. 733v.

28. AHN, Consejos, 20374, exp. 1, pieza 1, f. 734r.

29. Profundizar el examen de la visita de Luján de Vargas en el resto de las ciudades podrá contribuir a evaluar esta interpretación. 


\section{Referencias}

AGÜERO, Alejandro. 2007. "Las categorías básicas de la cultura jurisdiccional". In: Marta Lorente Sariñena (coord.). De justicia de jueces a justicia de leyes: hacia la España de 1870. Cuadernos de Derecho Judicial 6. Madrid: Consejo General del Poder Judicial. pp. 20-58.

ARCHIVO HISTÓRICO NACIONAL (AHN), Madrid. 1753-1792. Residencia de Juan Martinez de Tineo, gobernador de Tucumán. Consejos, 20374, expediente 1 y Consejos, 20375, expediente 1.

BARTON, David \& PAPEN, Uta. 2010. "What is the anthropology of writing?". In: . The anthropology of writing: understanding textually mediated worlds. London: Continuum International. pp. 3-32.

BELL, Catherine. 1992. Ritual theory, ritual practice. New York: Oxford University Press.

BENSA, Alban 2010. "Antropología e historia". ISTOR, Revista de Historia Internacional, 10(40):108-116.

BIXIO, Beatriz. 2009. "Introducción: notas de lectura de la Visita de Luxan de Vargas al Tucumán colonial”. In: . (dir.). Visita a las encomiendas de indios de Córdoba: transcripción y estudios sobre la visita de Antonio Martines Luxan de Vargas. Córdoba: Centro de Estudios Históricos Prof. Carlos S. A. Segreti, Editorial Brujas. pp. 7-40.

BLOCH, Maurice. 1977. "The past and the present in the present". Man, 12:278-292.

BOIXADÓS, Roxana. 2002. "Los pueblos de indios de La Rioja colonial: tierra, trabajo y tributo en el siglo XVII”. In: Judith Farberman. y Raquel Gil Montero (comp.). Los pueblos de indios del Tucumán colonial: pervivencia y desestructuración. Buenos Aires: Universidad Nacional de Jujuy y Universidad Nacional de Quilmes. pp. 15-57.

2003. "La visita de Luján de Vargas a las encomiendas riojanas (1693): comentarios, notas y lecturas posibles". In: Roxana Boixadós \& Carlos Zanolli. La visita de Luján de Vargas a las encomiendas de La Rioja y Jujuy (1693-1694): estudios preliminares y fuentes. Buenos Aires: Universidad Nacional de Quilmes. pp. 21-40.

BOIXADÓS, Roxana \& ZANOLLI, Carlos. 2003. "Ciudad de la Rioja: visita que se hizo de los indios de las encomiendas de la ciudad de La Rioja por el señor doctor Don Antonio Martínez Luján de Vargas del Consejo de su Majestad oidor de la Real Audiencia de la Plata - Pieza 5". In: Roxana Boixadós \& Carlos Zanolli, La visita de Luján de Vargas a las encomiendas de La Rioja y Jujuy (1693-1694): estudios preliminares y fuentes. Buenos Aires: Universidad Nacional de Quilmes. pp. 67-277. 
BOURDIEU, Pierre. 2013. Argelia 60: estructuras económicas y estructuras temporales. Buenos Aires: Siglo XXI. Publicado originalmente en 1977.

CASTRO OLAÑETA, Isabel. 2007. "Indios encomendados, indios registrados, indios omitidos por el visitador Lujan de Vargas. Salta, Gobernación de Tucumán, siglo XVII”. XI Jornadas Interescuelas y Departamentos de Historia (CD). UNT.

DOUCET, Gastón. 1980a. "Los autos del visitador don Antonio Martínez Luján de Vargas". Revista de Historia del Derecho, 8:123-153.

1980b. "Introducción al estudio de la visita del oidor don Antonio Martínez Luján de Vargas a las encomiendas de indios del Tucumán”. Boletín del Instituto de Historia Argentina y Americana Dr. Emilio Ravignani, 26:205-246.

DURKHEIM, Émile. 2007. Las formas elementales de la vida religiosa. Madrid: Akal. Publicado originalmente en 1912.

DURKHEIM, Émile \& MAUSS, Marcel. 1971. "De ciertas formas primitivas de clasificación: contribución al estudio de las representaciones colectivas". In: Marcel Mauss. Instituciones y culto: obras II. Barcelona: Barral. Publicado originalmente en 1903. ELIAS, Norbert. 2010. Sobre el tiempo. México: FCE. Publicado originalmente en 1984. EVANS-PRITCHARD, Edward Evan. 1977. Los Nuer. Barcelona: Anagrama. Publicado originalmente en 1940.

FABIAN, Johannes. 1983. Time and the other: how anthropology makes its object. New York: Columbia University Press.

FARBERMAN, Judith. 1991. "Indígenas, encomenderos y mercaderes: los pueblos de indios santiagueños durante la visita de Luján de Vargas (1693)". Anuario IEHS, 6:43-57.

. 2002. "Feudatarios y tributarios a fines del siglo XVII. Tierra, tributo y servicio personal en la Visita de Luján de Vargas a Santiago del Estero (1693)". In: Judith Farberman \&Raquel Gil Montero (comp.). Los pueblos de indios del Tucumán colonial: pervivencia y desestructuración. Buenos Aires: Universidad Nacional de Jujuy y Universidad Nacional de Quilmes. pp. 59-90.

FARBERMAN, Judith \& BOIXADÓS, Roxana. 2006. "Sociedades indígenas y encomienda en el Tucumán Colonial: un análisis comparado de la visita de Luján de Vargas". Revista de Indias, LXVI(238):601-628.

2009-2010. "Una cartografía del cambio en los pueblos de indios coloniales del Tucumán: autoridades étnicas, territorialidad y agregaduría en los siglos XVII al XIX”. Revista Histórica, XLIV:113-146. 
GEERTZ, Clifford. 1992. "Persona, tiempo y conducta en Bali". In: La interpretación de las culturas. Barcelona: Gedisa. pp. 299-238. Publicado originalmente en 1973.

GELL, Alfred. 1992. The anthropology of time. London: Berg.

GONZÁlEZ NAVARRO, Constanza. 2009. "Córdoba desde su fundación hasta la visita de Antonio Martines Luxan de Vargas". In: Beatriz Bixio (dir.). Visita a las encomiendas de indios de Córdoba: transcripción y estudios sobre la visita de Antonio Martines Luxan de Vargas. Córdoba: Centro de Estudios Históricos Prof. Carlos S. A. Segreti, Editorial Brujas. pp. 67-114.

GRANA, Romina. 2009. "Las mascaras del honor". In: Beatriz Bixio (dir.). Visita a las encomiendas de indios de Córdoba: transcripción y estudios sobre la visita de Antonio Martines Luxan de Vargas. Córdoba: Centro de Estudios Históricos Prof. Carlos S. A. Segreti, Editorial Brujas. pp. 115-131.

GUEVARA-GIL, Armando \& SALOMON, Frank. 1994. "A 'personal visit': colonial political ritual and the making of Indians in the Andes". Colonial Latin American Review, 3(1-2):3-36.

HALLOWELL, A. 1955. "Temporal orientations in Western civilization and in a preliterate society”. In: Culture and experience. Philadelphia: Pennsylvania University Press. pp. 216-35. Publicado originalmente en 1937.

HERZOG, Tamar. 2000. Ritos de control, prácticas de negociación: pesquisas, visitas y residencias y las relaciones entre Quito y Madrid (1650-1750). Madrid: Fundación Histórica Tavera.

HULL, Matthew. 2012. "Documents and bureaucracy". Annual Review of Anthropology, 41:251-267.

IARZA, Valeria. 2009. "La visita y las visitas". In: Beatriz Bixio (dir.). Visita a las encomiendas de indios de Córdoba: transcripción y estudios sobre la visita de Antonio Martines Luxan de Vargas. Córdoba: Centro de Estudios Históricos Prof. Carlos S. A. Segreti, Editorial Brujas. pp. 41-62.

KANTOROWICZ, Ernest. 1985. Los dos cuerpos del rey: un estudio de teología politica medieval. Madrid: Alianza. Publicado originalmente en 1957.

LE GOFF, Jacques. 1983. A civilização do ocidente medieval. Lisboa: Estampa. v. 1. Publicado originalmente en 1964.

LORANDI, Ana María. 1988. "El servicio personal como agente de desestructuración en el Tucumán Colonial”. Revista Andina, 3(1):135-170. 
MALINOWSKI, Bronislaw. 1927. "Lunar and seasonal calendar in the Trobriands". Journal of the Royal Anthropological Institute, 57:203-215.

MARILUZ URQUIJO, José María. 1952. Ensayo sobre los Juicios de Residencia indianos. Sevilla: Escuela de Estudios Hispanoamericanos.

MAUSS, Marcel. 1974. "Ensaio sobre as variações sazoneiras das sociedades esquimó". In: ______. Sociologia e antropologia. São Paulo: EPU. pp. 237-293. Publicado originalmente en 1904-1905.

MUNN, Nancy D. 1992. "The cultural anthropology of time: a critical essay". Annual Review of Anthropology, 21:93-123.

NOLI, Estela. 2003. "Pueblos de indios, indios sin pueblos: los calchaquíes en la visita de Luján de Vargas de 1693 a San Miguel de Tucumán”. Anales Nueva Época, 6:329-363.

PALMEIRA, Moacir. 2001. "Política e tempo: nota exploratória”. In: Mariza Peirano (org.). O dito e o feito: ensaios de antropologia dos rituais. Rio de Janeiro: Relume Dumará. pp. 171-177.

PEIRANO, Mariza. 2001. "A análise antropológica de rituais". In: (org.). $O$ dito e o feito: ensaios de antropologia dos rituais. Rio de Janeiro: Relume Dumará. pp. $17-40$.

PEIRCE, Charles. 1955. "Logic as semiotic: the theory of signs"; "The principles of phenomenology"; "How to make our ideas clear". In: Justus Buchler (ed.). Philosophical writings of Peirce. New York: Dover. pp. 23-41; 98-119.

POCOCK, John G. A. 1987. The Ancient Constitution and the Feudal Law: a study of English historical thought in the seventeenth century. London: Cambridge University Press. Publicado originalmente en 1957.

SMIETNIANSKY, Silvina. 2010. "Tiempo y ritual. Una aproximación al análisis de las representaciones del orden en la sociedad colonial (Gobernación del Tucumán, siglos XVII y XVIII)". Revista del Museo de Antropología, 3:99-112.

2012. "El estudio de las instituciones del gobierno colonial. Una aproximación etnográfica al juicio de residencia como ritual". Corpus: Archivos Virtuales de la Alteridad Americana, 2(1):1-32.

2013. Ritual, tiempo y poder. Una aproximación antropológica a las instituciones del gobierno colonial (Gobernación del Tucumán, siglos XVII y XVIII). Rosario: Prohistoria. 2015. "Tempo, oralidade e escrita: a sociedade hispânica colonial através do estudo de um procedimento judicial”. Sociologia \& Antropologia, 5(2):435-459. 
SMITH, Thomas C. 1986. "Peasant time and factory time in Japan". Past and Present, 111:165-197.

STOLER, Ann L. 2002. "Colonial archives and the arts of governance". Archival Science, 2:87-109.

TAU ANZOÁTEGUI, Víctor. 2001. El poder de la costumbre: estudios sobre el Derecho Consuetudinario en América hispana hasta la Emancipación. Buenos Aires: Instituto de Investigaciones de Historia del Derecho.

THOMPSON, Edward P. 1967. “Time, work-discipline, and industrial capitalism”. Past and Present, 38(1):56-97.

VALERI, Valerio. 1990. "Constitutive history: genealogy and narrative in the legitimation of Hawaiian kingship". In: Emiko Ohnuki Tierney. Culture through time: anthropological approaches. Stanford: Stanford University Press. pp. 117-155.

ZANOLLI, Carlos. 2003. "Análisis de la visita de Luján de Varas a la jurisdicción de San Salvador de Jujuy (1694)". In: Roxana Boixadós \& Carlos Zanolli. La visita de Luján de Vargas a las encomiendas de La Rioja y Jujuy (1693-1694): estudios preliminares y fuentes. Buenos Aires: Universidad Nacional de Quilmes. pp. 41-63. 


\section{Resumen}

Este artículo constituye una aproximación etnográfica al estudio del tiempo en la sociedad de Hispanoamérica colonial a través del examen comparativo de dos dispositivos con que contaba la Corona en la administración de sus dominios: la visita y el juicio de residencia. En continuidad con trabajos anteriores, la conceptualización de estos eventos como rituales marca la orientación y las claves de un análisis interesado en explorar los modos de registro y representación del tiempo. Se examinan dos casos: la visita a los indios encomendados del Tucumán sustanciada en 1692-1694 por un Oidor de la Audiencia de Charcas, y, el juicio de residencia instruido al gobernador del Tucumán Juan Victorino Martínez de Tineo en 1763-1764.

\section{Abstract}

This article proposes an ethnographic approach to the study of time in Hispanic American colonial society, by examining comparatively two procedures that the Crown used for the administration of their domains: the visita and the juicio de residencia. In continuity with previous research, the conceptualization of these events as rituals defines the orientation and the keys of an analysis interested in exploring the ways to record and represent time. Two cases are examined: the visita to the indios encomendados of the Tucumán province, conducted by Antonio Martinez Luján de Vargas, a functionary of the Audiencia de Charcas, and the juicio de residencia impeached to Juan Victorino Martinez de Tineo, who was governor of that jurisdiction (1763-1764).

Palabras-clave: tiempo, ritual, visita, Key-words: time, ritual, visita, juicio juicio de residencia, Tucumán colonial. de residencia, colonial Tucumán. 